\title{
Modal Analysis of Pipe/Panel Structure in Airplane
}

\author{
CHEN ZHENZHONG ${ }^{1, a^{*}}$, ZU WEIHUA ${ }^{2, b}$ \\ ${ }^{1,2}$ Faculty of Aerospace Engineering, Shenyang Aerospace University, Shenyang, LN 110136, \\ China \\ a1519973295@qq.com, b371525159@qq.com
}

Keywords: pipe/panel structure; modal ; working frequency; ANSYS/Workbench

Abstract. The finite element model of pipe/shell structure is established using Design/Modeler of ANSYS/Workbench. The modal analysis of the pipe/shell structure is done at $28 \mathrm{MPa}$ of stable pressure by ANSYS/Workbench, the first six order frequency and vibration model are obtained. The third natural frequency is close to the working frequency and the maximum deformation is around the corner of the pipe from the deformation cloud diagram. The natural frequencies are increased by adding constraints, and avoiding the working frequencies. The results can be the references for the design and optimization.

\section{Introduction}

The hydraulic pipe/panel structure is the typical structure in aircraft. Pressure pulse of the hydraulic oil in pipe cause the vibration of the pipe and connected panel, even lead to fatigue and even fracture of the hydraulic pipe because of resonance when exciting frequency is close to the natural frequency of the structure ${ }^{[1,2]}$.

Recently, studies of vibration absorption about hydraulic pipe and panel structures have been conducted respectively, but few study is about vibration of pipe/panel structure, therefore, it is important to carry out modal analysis of pipe/panel structure and to propose scheme of vibration absorption $^{[3-8]}$.

The finite element modal was built with the Geometric modeling platform-Design Modeler of ANSYS Workbench on the base of analyzing the structure features and working conditions, and pre-stress modal analysis of the pipe/panel structure was carried out in this paper.

\section{Modal analysis theory}

Hamilton's principle is as following:

$\delta \int_{0}^{T}[K-(U-W)] d t=0$

where:

$$
\begin{aligned}
& K=\iint_{\Omega} \rho\left(\frac{\partial \mathbf{u}}{\partial t}\right)^{\mathrm{T}} \delta \frac{\partial \mathbf{u}}{\partial t} d z d x d y \\
& U=\int_{\Omega}(\boldsymbol{\sigma})^{\mathrm{T}} \delta \boldsymbol{\varepsilon} d z d x d y \\
& W=\int_{\Omega} \overline{\boldsymbol{f}}^{\mathrm{T}} \delta \mathbf{u} d x d y+\int_{\partial \Omega} \overline{\boldsymbol{T}}^{\mathrm{T}} \delta \mathbf{u} d s
\end{aligned}
$$


$\mathrm{K} 、 \mathrm{U}$ and $\mathrm{W}$ are kinetic energy, internal energy and external work respectively, and $\rho$ is material density; $f$ is body force, $\overline{\boldsymbol{T}}$ is boundary force.

Ignoring the influence of damping, vibration balance equation is given as following:

$$
\boldsymbol{M}^{e}(t)+\boldsymbol{K}^{e} \boldsymbol{\delta}^{e}(t)=\boldsymbol{Q}(t)
$$

Where $\boldsymbol{M}^{\boldsymbol{e}}$ is unit masse matrix, $\boldsymbol{K}^{\boldsymbol{e}}$ is unit stiffness matrix, $\boldsymbol{\delta}^{\boldsymbol{e}}$ is node free vector, $\boldsymbol{Q}(t)$ is node loading vector. $\boldsymbol{M}^{\boldsymbol{e}}$ and $\boldsymbol{K}^{\boldsymbol{e}}$ can be given as:

$$
\mathbf{K}^{e}=\int_{v_{e}} \mathbf{B}^{\mathrm{T}} \mathbf{Q B} d V
$$

Where $\mathbf{B}$ is unit strain matrix, $\mathbf{Q}$ is elastic constant.

$$
\mathbf{M}^{e}=\int_{v_{e}} \rho \mathbf{N}^{\mathrm{T}} \mathbf{N} d V
$$

Where $\rho$ is material density, $\mathbf{N}$ is shape function.

The unit stiffness matrix and masse matrix are assembled in the global coordinate system, the dynamic equilibrium equation can be given:

$$
\left(\mathbf{K}-\omega^{2} \mathbf{M}\right) \delta=\mathbf{Q}(t)
$$

Where $\mathbf{K}$ is global stiffness matrix, $\mathbf{M}$ is global masse matrix, $\boldsymbol{\omega}$ is system natural frequency.

\section{Modal analysis}

The 3D modal of pipe/panel structure is built by platform-Design Molder of ANSYS Workbench (seen in Fig.1). The outside diameter of pipe is $16 \mathrm{~mm}$, the thickness is $1 \mathrm{~mm}$, material is $1 \mathrm{cr} 18 \mathrm{ni} 9 \mathrm{ti}$, the density is $7750 \mathrm{~kg} / \mathrm{m}^{3}$, elastic modulus is $193 \mathrm{GPa}$, Poisson's ratio is 0.30 . The material of panel and pipe clamp is LY12, density is $2780 \mathrm{~kg} / \mathrm{m}^{3}$, elastic modulus is $200 \mathrm{GPa}$, Poisson's ratio is 0.31 . The pressure in the pipe is $28 \mathrm{MPa}$.

Hexahedron units(Solid 187) are adopted to mesh the panel, and tetrahedral units (Solid186) are adopted to mesh the pipe. The panel is meshed automatically. Mapped Face Meshing is used to mesh the pipe joint because of its high thickness, and the joint of pipe and the panel are disposed by mesh refinement, and 25891 units and 110479 nodes are created in this process. The boundary conditions of the structure are given as following: upper and lower end of panel as well as both ends of the pipe are fixed, the connection surfaces of pipe and pipe clamp are defined as friction support.

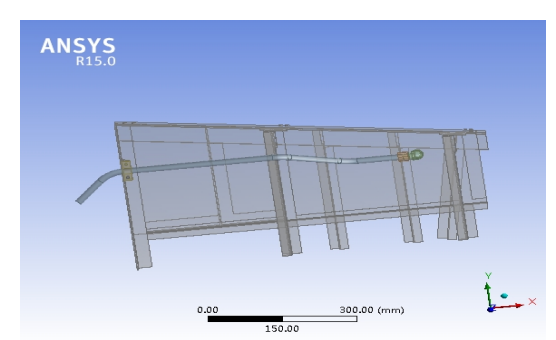

Fig.1 Model of the structure 
The first six orders of natural frequencies and modal shapes are acquired, the frequencies are given in Table.1, and mode shapes are given in Fig.2.

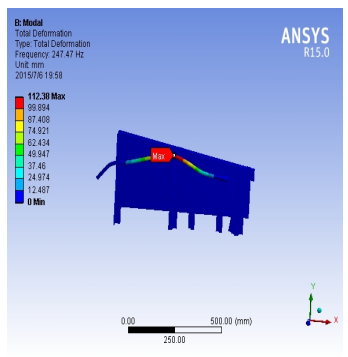

(a)The first order

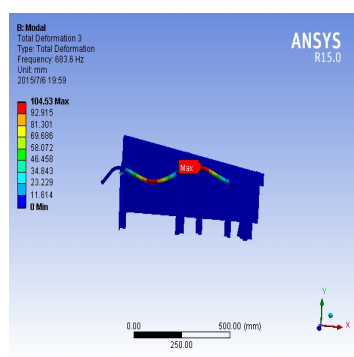

(c)the forth order

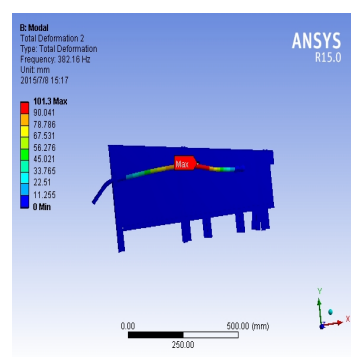

(b)the second order

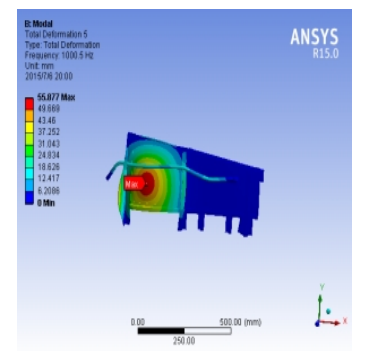

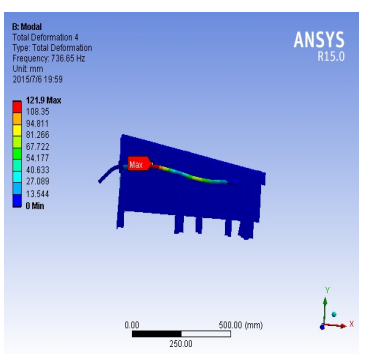

(c) the third order

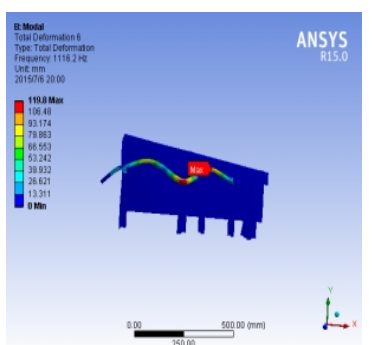

(d) the fifth order

(f) the sixth order

Fig.2. First six order mode shape

The principal shape of first mode shape is pipe's Y-axial oscillation in Fig.2(a). The principal shape of second mode shape is pipe's Z-axial oscillation in Fig.2(b). The principal shape of third mode shape is pipe's Y-axial oscillation in Fig.2(c). The principal shape of forth mode shape is pipe's Y-axial and Z-axial oscillation in Fig.2(d). The principal shape of fifth mode shape is Z-axial oscillation of middle part of pipe and the panel in Fig.2(e). The principal shape of sixth mode shape is $\mathrm{Y}$-axial and Z-axial oscillation of the middle part of the pipe in Fig.2(f).

The third natural frequency of the structure in Table. 1 is close to the exciting frequency, which may trigger resonance. The maximum distortion is at the pipe's corner showed in Fig.2, therefore, adding constraints at the corner is used to improve vibration of the structure showed in Fig. 3. The first six orders natural frequencies of the improved structure are showed in Table2, and the frequencies are larger and avoiding the resonance by adding support at $\mathrm{C}$ and $\mathrm{D}$ to restrict $\mathrm{Y}$ and $\mathrm{Z}$ axial displacement and rotation and to set $\mathrm{X}$ axis free.

Table. 1. Natural frequencies of the structure

\begin{tabular}{|c|c|}
\hline Modal order & Natural frequency $(\mathrm{Hz})$ \\
\hline 1 & 247.47 \\
\hline 2 & 382.16 \\
\hline 3 & 683.60 \\
\hline 4 & 736.65 \\
\hline 5 & 1000.5 \\
\hline 6 & 1116.2 \\
\hline
\end{tabular}

Table.2. Natural frequencies of the improved structure

\begin{tabular}{|c|c|}
\hline Modal order & Natural frequency $(\mathrm{Hz})$ \\
\hline 1 & 1004.7 \\
\hline 2 & 1059.2 \\
\hline 3 & 1085.8 \\
\hline 4 & 1482.9 \\
\hline 5 & 1605.7 \\
\hline 6 & 1641.5 \\
\hline
\end{tabular}

\section{Summary}

The finite element modal of the pipe/panel structure was built with the Geometric modeling platform-Design Modeler of ANSYS Workbench, pre-stress modal analysis was carried out and the structure's first six mode shapes were got. The maximum distortion and stress are at the pipe's 
corner, which may lead fatigue crack and even fracture. The frequencies of improved structure by adding supports at the corner of the pipe increased and avoided resonance.

\section{References}

[1]ZHANG Guo-zhi, SHA Yun-dong, ZHU lin, Calculation and analysis on vibration response of thin-panels under random acoustic load[J]. Journal of Shenyang Aerospace University, 2014,8: 24-28.

[2] WANG Fu-mao, XU Zong-ling, Dynamic characteristic Analysis of Fluid-filled Pipe under the Action of Fluctuating Pressure.[J]ISE AND VIBRATION CONTROL,2013,4(2):11-14.

[3] LIANG Jian-shu, SU Qiang, Modal Analysis of Fluid-Structure Interaction Bellows Based on ANSYS/Workbench. [J]. Machinery Design \& Manufacture, 2013,2: 91-93.

[4] Zahedineja P, Malekzadeh P. A semi-analytical three-dimensional free vibration analysis of functionally graded curved panels [J]. J Eng Math,2009,63:95-119.

[5]WANG Jing, CHEN Guo, Effect of Clamp on Aircraft Hydraulic Pipeline Dynamic Stress. [J]. Aeronautical Computing Technique. 2014,1:64-72.

[6]XIE An-huan, KE Yin-yan, Analysis on vibration Characteristics of Hydraulic Pipe by the Incentives of Pulsating Flow. [J].Chinese Hydraulics and Pneumatics. 2014,9:117-120.

[7]LI Sheng-quan, LI Juan, Piezoelectric multi-mode vibration control of stiffened plate using active disturbance rejection method. [J].Control Theory \& Applications.

[8]LI Jing, WANG Kangjing, Effect of Periodic Pulsation Fluid on Vibration Characteristics of Hydraulic Pipe of Aircraft. [J].MACHINE TOOL \& HYDRAULICS, 2014,6 5-8. 